\title{
Entre el miedo y la distinción. El estado actual del fraccionamiento cerrado en las ciudades fronterizas de Tijuana, Nogales y Ciudad Juárez
}

\author{
Jesús Ángel Enríquez Acosta*
}

\begin{abstract}
Resumen. En las ciudades de Tijuana, Nogales y Ciudad Juárez, ubicadas en la frontera noroeste entre México y Estados Unidos, uno de los procesos de urbanización que se ha extendido en los últimos años es la modalidad del fraccionamiento cerrado. Estas áreas residenciales se caracterizan por ser espacios físicos protegidos y separados de los disturbios de la ciudad por bardas y rejas, y en su mayoría presentan un acceso restringido por medio de casetas, plumas y seguridad proporcionada por guardias privados. El concepto de fraccionamiento cerrado tiende a expandirse en el paisaje urbano de las ciudades fronterizas sin más restricciones que las que el mercado inmobiliario se impone a sí mismo, no obstante, es importante analizar su impacto en la morfología de las ciudades, la sustentabilidad urbana de estos desarrollos y la segregación social que propician. Palabras clave: ciudades fronterizas, fragmentación urbana, segregación social.
\end{abstract}

\begin{abstract}
A bstract. In the cities of Tijuana, Nogales and Ciudad Juárez, located in the northwestern border between Mexico and the United States, one of the more popular urbanization processes is the modality of closed divisions. These residential areas are characterized for being a physical space protected and separated from the city disturbances with bars and fences, and most of them present monitoring houses with access restrictions and private surveillance. The concept of closed divisions tends to expand in the urban landscape of the border cities without restrictions except for those established by the real estate market. N evertheless, it's important to analyze the impact of closed divisions in the morphology of the cities, the urban sustentability of this developments and the social segregation they cause. Keywords: border cities, urban fragmentation, urban segregation
\end{abstract}

* Departamento de Sociología y Administración Pública. Universidad de Sonora. Correo electrónico: jesusenriquez@sociales.uson.mx 


\section{Introducción}

Este trabajo estudia el fenómeno de los fraccionamientos cerrados ${ }^{1}$ en las ciudades fronterizas de Tijuana, Nogales y Ciudad Juárez, ubicadas en el noroeste de México. En estas ciudades, el proceso de urbanización predominante en los últimos años se basa en conjuntos residenciales provistos de muros perimetrales, casetas de vigilancia, uso de guardias privados y restricciones para el acceso, con el objeto de dotar a sus habitantes de seguridad, privacidad y distinción social. Bajo los supuestos de la inseguridad y el miedo a la violencia en las ciudades fronterizas, se ha fomentado la construcción de desarrollos habitacionales en la modalidad de fraccionamientos cerrados, acentuando con ello la fragmentación urbana y la segregación social y privatizando el espacio público. El fraccionamiento cerrado, que en sus inicios se presentaba como una alternativa de exclusividad social para las clases medias y altas, ha empezado a atravesar a todos los estratos sin limitarse a una sola condición socioeconómica. Algunos indicios nos hacen suponer que este modelo tiende a masificarse y expandirse a todos los grupos sociales.

El fraccionamiento cerrado no es una salida al desorden urbano o al caos característico de las ciudades fronterizas; por el contrario, es un fenómeno que construye un escenario urbano cada vez más articulado alrededor de los muros que imposibilitan la legibilidad y visibilidad de las ciudades. Podría decirse que existe una analogía entre el despliegue del muro fronterizo - cuya finalidad es dividir a las naciones en las ciudades estudiadas e impedir la entrada de inmigrantes que buscan la oportunidad del sueño americano - y la instauración de muros al interior de las ciudades. Los muros urbanos defienden de la intromisión del otro, excluyen al extraño a fuerza de establecer barreras físicas, protegiendo los usos privados del espacio público.

\footnotetext{
${ }^{1}$ Por fraccionamiento cerrado entendemos todo conjunto urbano provisto de un único acceso controlado, con bardas perimetrales y vigilancia privada en los accesos. Generalmente, el régimen condominal es el tipo de propiedad que da sustento jurídico a este tipo de viviendas. Las limitaciones topográficas, tales como cerros y cañadas, refuerzan el cierre del conjunto urbano.
} 
El presente documento ${ }^{2}$ tiene como propósito presentar un primer acercamiento al panorama general de los fraccionamientos cerrados en las ciudades fronterizas de Tijuana, Nogales y Ciudad Juárez. Se analiza el impacto del fraccionamiento cerrado en la morfología e imagen urbana de las ciudades, la expansión de la segregación residencial, ${ }^{3}$ las características de seguridad y la sustentabilidad urbana que este tipo de desarrollos representa. Este análisis, básicamente descriptivo, se apoya en la información obtenida a partir de un censo de los fraccionamientos cerrados elaborado por el equipo de investigación durante los recorridos de campo. Para recabar la información se utilizó un formato de registro por cada uno de los fraccionamientos cerrados detectados, en el que se recogieron el tipo y nivel de seguridad, las características arquitectónicas y urbanas, la disposición y tipo de infraestructura y equipamiento y la condición socioeconómica de los residentes. Asimismo, se realizó un registro fotográfico de los espacios detectados y de las ciudades estudiadas.

\section{Breve estado de la cuestión del fraccionamiento cerrado en las ciudades fronterizas}

Estudiar el fenómeno de los fraccionamientos cerrados en la frontera noroeste de México proporciona la oportunidad de poner a prueba los enfoques teóricos utilizados en Estados Unidos y Latinoamérica para el análisis de este fenómeno urbano, aprovechando la contigüidad de las ciudades fronterizas mexicanas con el país donde dio inicio este proceso.

$\mathrm{Al}$ respecto son importantes los análisis realizados por Méndez y Rodríguez (2004), quienes se acercaron por primera vez al estudio de los fraccionamientos cerrados en las ciudades de la frontera entre México y Estados Unidos. En el marco de su vecindad con Estados

\footnotetext{
${ }^{2}$ Este trabajo se inscribe dentro de la investigación financiada por el Conacyt "Comunidades cercadas: estudio de una arquitectura y urbanismo alternativos a la luz de la experiencia de la frontera norte de México, 1980-2003", bajo la dirección de Eloy Méndez, investigador de El Colegio de Sonora.

${ }^{3}$ Por segregación residencial entendemos "el grado de proximidad espacial o de aglomeración territorial de las familias pertenecientes a un mismo grupo social, sea que éste se defina en términos étnicos, etarios, de preferencias religiosas o socioeconómicas, entre otras posibilidades" (Sabatini, Cáceres y Cerda, 2001).
} 
Unidos, las ciudades fronterizas presentan marcados procesos de polarización social y de crecimiento demográfico, desde los cuales los fraccionamientos cerrados van llenando los intersticios dejados por el desarrollo urbano y se convierten en la principal oferta para las clases altas dejando la periferia para los otros grupos sociales. La dispersión y la ciudad inmanejable son la consecuencia de estos procesos. Para estos autores, los fraccionamientos cerrados se encargan de abastecer satisfactores materiales entre la población, simulando la seguridad y el confort mediante artificios de tipo escenográfico que recrean la puesta en escena de una versión local como caricatura de sus contrapartes en otros países.

Pensando en el tipo de urbanismo y arquitectura dispuesta en el espacio de las ciudades fronterizas, Méndez (2006) retoma las experiencias tempranas de encerramiento observadas en México para llegar al fraccionamiento cerrado como lo conocemos hoy en día, con las bardas, la ostentosidad interior que destaca ante la pobreza de los entornos circundantes y el sentido de comunidad artificialmente construido a modo de las clases acomodadas. El urbanismo representado por el fraccionamiento cerrado asume a las ciudades como facilitadoras de la competitividad del mercado inmobiliario bajo las premisas de privilegiar y excluir. La arquitectura del fraccionamiento cerrado es un recurso escenográfico utilizado para idealizar lo comunitario basándose en mensajes presuntamente tradicionales, pero recontextualizados para la situación fronteriza como mero accesorio de consumo. A consideración de Méndez, prevalece la simulación en la arquitectura y una propuesta urbana que reniega de la ciudad preexistente en vez de construir alternativas "abiertas, amables, incluyentes, ambientalmente racionales".

Por su parte, Rodríguez (2006) observa que en las ciudades fronterizas prevalece un modelo urbano que refuerza la fragmentación urbana y la segregación social. Tanto la fragmentación como la segregación en buena medida son propiciadas por el mercado inmobiliario que encabeza el proyecto de ciudad cerrada a falta de una eficaz intervención pública en la hechura urbana que favorezca el interés colectivo sobre el privado. Rodríguez concluye que las inmobiliarias imponen un concepto urbano basado en el rápido montaje de viviendas que fácilmente envejecen y se desmantelan por la precarie- 
dad de las identidades prefabricadas dentro del paquete de venta de las viviendas. Sin embargo, la propuesta cerrada es un tipo de urbanización que no sólo se ofrece a las elites fronterizas, sino que también, y sobre todo a últimas fechas, se ha abierto en alguna medida a otros grupos sociales. Éste es un producto apreciado y demandado por los compradores de vivienda, pero sus consecuencias urbanas todavía no son previsibles.

Para López (2005), los fraccionamientos cerrados de las ciudades fronterizas, en particular en Nogales, pueden explicarse a partir del poder del mercado inmobiliario para hacer ciudad, y en cierta medida como respuesta a la inseguridad existente, pero sobre todo por los imaginarios de la población que aceptan la propuesta cerrada dada la fragmentación de la ciudad por la fisonomía montañosa y la situación fronteriza que acerca las diferencias entre las naciones vecinas, a pesar de la exclusión y la segregación expresada por el fraccionamiento cerrado.

Teniendo como referencia a Ciudad Juárez y las políticas de vivienda gubernamentales seguidas en los últimos años, Maycotte (2005) introduce una variable que explica en buena medida el éxito inmobiliario de los fraccionamientos cerrados: la figura del condominio. Esta autora considera que el marco legal existente da cobertura a políticas que tienden a reducir las condiciones de habitabilidad de las viviendas de interés social mediante el régimen de condominio; esta forma de propiedad permite disminuir el tamaño de las viviendas y restringir las posibles ampliaciones a las mismas, además de convertir a las exiguas áreas comunes en áreas residuales que no promueven la convivencia vecinal. Cosa distinta ocurre con los conjuntos residenciales medios y altos, en los que el ornamento es fundamental.

En las ciudades fronterizas de Tijuana, Nogales y Ciudad Juárez, los fraccionamientos cerrados han proliferado en los últimos 15 años y en algunas ciudades son casi la única forma de urbanización disponible. El fenómeno tiene particularidades locales que lo distinguen de otras ciudades latinoamericanas, no sólo por el contexto del muro que separa a México y Estados Unidos sino por el tipo y la extensión del proceso de fragmentación urbana y segregación social propiciado por el mercado inmobiliario que no tiene contraparte activa en la dimensión pública. 


\section{Las consecuencias del fraccionamiento cerrado en las ciudades fronterizas}

En las ciudades fronterizas el fenómeno de los fraccionamientos cerrados ha experimentado un importante crecimiento, constituyéndose a últimas fechas en una de las principales opciones para adquirir vivienda dentro de los conjuntos urbanos de nueva creación. En el trabajo de investigación ${ }^{4}$ realizado en Tijuana, Nogales y Ciudad Juárez se pudo constatar que la mayoría de los nuevos emprendimientos tienen como principal atributo el de venderse bajo el régimen de propiedad en condominio, con regulaciones en el acceso y protegidos por bardas. En Tijuana ha sido importante el proceso de construcción de fraccionamientos cerrados en años recientes, siendo la figura del fraccionamiento abierto un asunto menos común. En el caso de Nogales los fraccionamientos cerrados se dirigen esencialmente a la clase media con la simbología mercadotécnica de la seguridad y el prestigio; los fraccionamientos abiertos de grandes dimensiones se destinan sobre todo a la clase trabajadora mediante los sistemas de financiamiento gubernamental del Infonavit y el FOVI. En Ciudad Juárez los fraccionamientos cerrados se orientan a las clases media y alta bajo el esquema de conjuntos de pequeñas dimensiones con atributos de prestigio, exclusividad y seguridad. Los fraccionamientos abiertos construidos en años recientes siguen una fórmula similar a su contraparte en Nogales, aunque los últimos grandes desarrollos de tipo popular emprendidos por las empresas Urbi, Viveica y Brasa introducen la opción cerrada.

En el caso de Tijuana, al ser el fraccionamiento cerrado uno de los principales mecanismos de desarrollo habitacional de la ciudad, su impacto en la morfología urbana ya es significativo. La creación de grandes espacios cerrados populosos en la periferia de la ciudad dificulta la continuidad urbana porque éstos no se ligan al resto de la mancha, sino que se ubican de manera separada, más bien aislada, propiciando problemas de congestionamiento vehicular en las esca-

\footnotetext{
${ }^{4}$ El trabajo de investigación fue realizado de octubre de 2004 a marzo de 2005 por un equipo integrado por arquitectos y sociólogos estudiantes de maestría y doctorado de El Colegio de Sonora y la Universidad de Sonora.
} 
sas vías primarias existentes. Además, la ausencia de escuelas, fuentes de empleo o áreas recreativas en los conjuntos cerrados vuelve difícil la vida cotidiana. Los conjuntos de nivel medio y alto se emplazan generalmente sobre zonas exclusivas y caras de la ciudad, densificando las áreas baldías pero reproduciendo de todas maneras un esquema escindido de la ciudad. En Nogales los fraccionamientos cerrados todavía no tienen un notable impacto en la ciudad por su bajo número y su orientación casi exclusiva hacia el sector socioeconómico de clase media, sin embargo es la única opción que el mercado inmobiliario provee para ellos.

En el caso de Ciudad Juárez, los conjuntos urbanos cerrados están orientados a las clases media y alta. Tradicionalmente se han establecido sobre el sector oriente de la ciudad, en el cual la ciudad presenta una imagen moderna gracias a las grandes inversiones públicas realizadas para la construcción de vialidades primarias que enlazan hacia el centro de la ciudad y a los puntos de cruce fronterizo. Esa modernidad también se representa por el establecimiento de grandes centros comerciales de cadenas nacionales y norteamericanas. Bajo esa premisa, el fraccionamiento cerrado en Ciudad Juárez reproduce un esquema que fragmenta y divide a la ciudad entre oriente y poniente, al mismo tiempo que la segregación residencial se instaura como un factor dominante.

Los fraccionamientos cerrados van configurando el escenario urbano bajo la imagen de la exclusividad y el prestigio para las clases sociales más pudientes, y de hacinamiento y alta conflictividad social en los de tipo popular o de interés social. El discurso de la inseguridad real o imaginaria justifica el establecimiento de muros para separarse de la ciudad, y dentro de los conjuntos cerrados el autogobierno implica otras formas de involucramiento de los residentes en las tareas de mantenimiento y creación de comunidad. La privatización del espacio público está representada por el conjunto cerrado a intromisiones externas, pero ello también implica que la hechura de las ciudades contemporáneas, y de las fronterizas en particular, no está pensado para fomentar la inclusión social, la tolerancia y la diversidad social. Ésas son las consecuencias del urbanismo defensivo en las ciudades fronterizas (Méndez, 2003). 
Del trabajo de investigación realizado en las ciudades fronterizas se desprende que los fraccionamientos cerrados han incrementado su número en los últimos 15 años, generalizándose como uno de los fenómenos urbanos más relevantes. Esos espacios no pueden caracterizarse sólo por sus connotaciones a la riqueza de determinados grupos sociales, pues también abarcan a un importante sector de clase media que desea mantener un estilo de vida. Es claro que existen diferencias en el tipo y en la forma de los fraccionamientos cerrados, así como en la calidad de los equipamientos para el esparcimiento y para la seguridad y privacidad; sin embargo, es evidente que los fraccionamientos cerrados son hoy en día un importante fenómeno urbano que tiene trascendencia por sus implicaciones en el futuro de las ciudades. A continuación se muestra de forma descriptiva el estado que guardan actualmente los fraccionamientos cerrados en las ciudades fronterizas de Tijuana, Nogales y Ciudad Juárez. Para este trabajo el análisis de la información se dividió en cuatro apartados: $a$ ) accesibilidad y legibilidad, b) seguridad y vigilancia, c) sustentabilidad urbana, y d) segregación urbana.

\section{Accesibilidad y legibilidad}

El boom inmobiliario observado en las ciudades fronterizas en los años recientes es importante. En las visitas realizadas a esas ciudades durante 2004 y 2005, la magnitud del desarrollo inmobiliario pudo constatarse por el importante número de fraccionamientos cerrados existentes y otros más en proceso de construcción. Tanto en Tijuana como en Nogales y Ciudad Juárez, el auge constructivo de conjuntos residenciales cerrados sin ningún tipo de planeación tiene un efecto sobre la legibilidad urbana pues hace invisibles los espacios e inasequibles los límites en el caso de topografías accidentadas, y crea fragmentos urbanos sobre campos agrícolas o en las periferias. Al mismo tiempo, las ciudades tienden a ser cada vez más inaccesibles por el levantamiento de muros de protección que interrumpen la secuencia urbana, así como por el mercado inmobiliario que selecciona los sectores más apropiados para maximizar el valor de las propiedades, como es el caso de los fraccionamientos cerrados exclusivos, o para 
minimizar los costos aumentando la densidad habitacional, para el caso de los grandes asentamientos cerrados de tipo popular.

La proliferación de fraccionamientos cerrados, tanto en la periferia de la ciudad como en su parte central, afecta la legibilidad urbana en el sentido de que no se pueden reconocer y organizar con facilidad las partes en una pauta coherente (Lynch, 1984). El levantamiento de bardas y muros de protección vuelven invisibles los espacios interiores, y de igual modo hace ilegible a la ciudad en el sentido de que no se permite la continuidad urbana ni se identifica la estética arquitectónica de los espacios desde el exterior de las bardas; sólo se distingue la frialdad que los muros imponen al ambiente y la soledad que impera en las calles adyacentes al espacio cerrado. Desprovistos de contactos sociales hacia el exterior, los fraccionamientos cerrados hablan de una ciudad que, en vez de legible, es impersonal, y antes de ser accesible, es excluyente.

En Tijuana, Nogales y Ciudad Juárez, la rápida proliferación de los fraccionamientos cerrados está produciendo un paisaje urbano donde las bardas y los muros perimetrales sustituyen a las fachadas de las viviendas en la traza básica de las ciudades (Musí, 2004). Estas fachadas, con sus particulares estilos arquitectónicos y jardines frontales con vistas a la calle, constituían la unidad y el sentido de las zonas residenciales, pero en la actualidad dicha unidad es referida por las barreras físicas que separan lo público, conformado por la calle y las banquetas, de lo privado, compuesto por los conjuntos residenciales ocultos a la vista. La discontinuidad urbana que refieren los fraccionamientos cerrados es fácilmente observable a partir de elementos materiales como bardas, muros y arcos de tipo monumental que identifican el espacio y al mismo tiempo se convierten en barreras y obstáculos para la integración urbana.

Se observa de inmediato que las ciudades reducen la permeabilidad urbana: la secuencia y continuidad se interrumpe en las bardas, los circuitos interiores son inaccesibles y el acceso vigilado es el único punto que liga el espacio cerrado con el resto de la ciudad. En ciudades como Tijuana o Nogales, la continuidad urbana se interrumpe aún más por las dificultades de la topografía montañosa, ya que el trazado urbano de los espacios cerrados utiliza los cerros y taludes 
como límites, pero también como elemento material que facilita aislar el espacio y ligarlo poco a las ciudades.

En Tijuana se detectaron $72^{5}$ fraccionamientos cerrados, de los cuales $45.8 \%$ corresponde a desarrollos en proceso de construcción (figura 1 y cuadro 1). Llama la atención en los fraccionamientos inconclusos que la promoción y venta de las viviendas se realizan durante el proceso mismo de construcción o incluso cuando sólo están proyectados. Entre los fraccionamientos en construcción ubicados sobresalen los grandes desarrollos del suroriente de la ciudad, como Hacienda de las Flores, El Dorado, Real de San Francisco, así como los sectores de El Florido y El Refugio (formados por un conglomerado de múltiples desarrollos más pequeños), cada uno conformado por miles de viviendas de interés social en régimen de condominio. Hacia el surponiente se encuentra Santa Fe, igualmente compuesta por varios miles de vi-

\section{Cuadro 1.}

Fraccionamientos cerrados terminados y en proceso de construcción, 2004-2005

\begin{tabular}{|c|c|c|c|c|c|c|}
\hline \multirow{2}{*}{ Ciudad Estado } & \multicolumn{2}{|c|}{ Terminado } & \multicolumn{2}{|c|}{ Inconcluso $^{a}$} & \multicolumn{2}{|c|}{ Total } \\
\hline & Abs. & $\%$ & Abs. & $\%$ & Abs. & $\%$ \\
\hline Tijuana & 39 & 54.2 & 33 & 45.8 & 72 & 100 \\
\hline Nogales & 8 & 72.7 & 3 & 27.3 & 11 & 100 \\
\hline Ciudad Juárez & 23 & 63.9 & 13 & 36.1 & 36 & 100 \\
\hline Total & 70 & 58.8 & 49 & 41.2 & 119 & 100 \\
\hline
\end{tabular}

a El que un fraccionamiento cerrado esté inconcluso no significa que no esté habitado, por el contrario, los conjuntos se desarrollan por etapas. Llamamos inconclusos a los conjuntos urbanos habitados donde todavía existen etapas de desarrollo en proceso de construcción y venta.

Fuente. Elaboración propia.

${ }^{5}$ Los fraccionamientos cerrados de Tijuana, Nogales y Ciudad Juárez fueron detectados en los recorridos de campo realizados durante 2004 y 2005. Cada uno de ellos fueron censados en fichas de registro que contemplaron las características de la vivienda, la seguridad, el equipamiento y la infraestructura, los requisitos de venta y el precio de la vivienda. 
viendas combinadas por secciones de interés social, popular y medio; Quinta Versalles, anexa al conjunto, es la versión más exclusiva y cara. Santa Fe ha pasado por varias etapas de crecimiento, encontrándose en el presente en su quinta etapa y formando todo el conjunto una ciudad separada del casco urbano.

Lo común en los desarrollos indicados es su ubicación al sur de Tijuana, formados por varios miles de viviendas y establecidos en la periferia de la ciudad. Estas circunstancias provocan problemas para la ciudad, entre los cuales se destacan su lejanía con la parte central o con los lugares de trabajo, incrementando los tiempos de movilización, el congestionamiento vehicular de las vialidades primarias, la alta densidad poblacional y las reducidas dimensiones de las viviendas que a su vez influyen en el hacinamiento de los conjuntos y en las deficiencias de los servicios básicos. Pero además de esos problemas, los espacios cerrados tienen un caracter inaccesible con respecto a la ciudad en el sentido de que se encuentran pobremente conectados

Figura 1.

Ubicación de fraccionamientos cerrados en Tijuana, 2004-2005

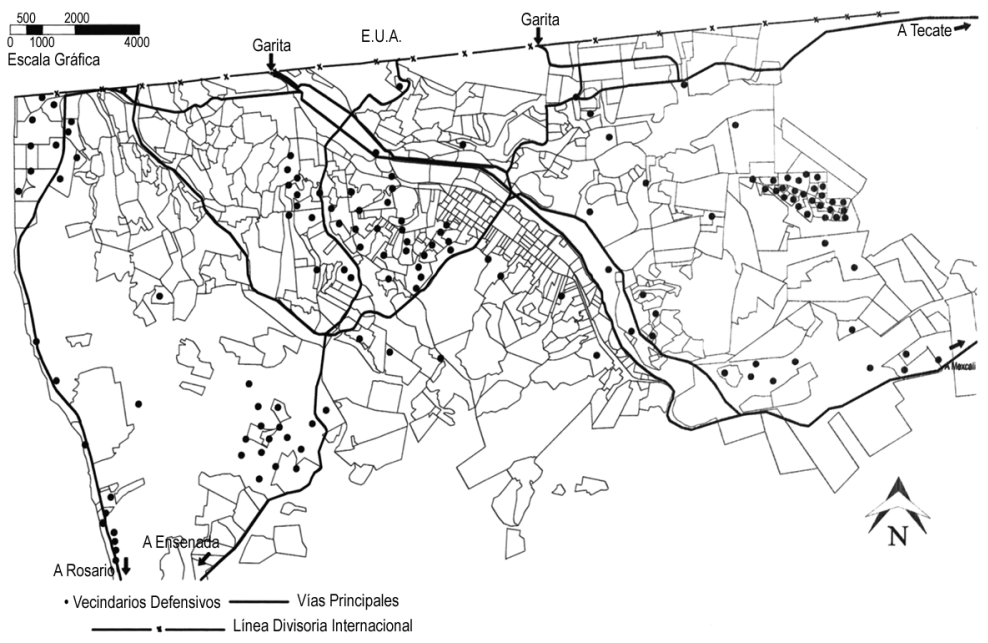

Fuente: Elaboración propia con base en las fichas de registro. 
entre sí y con el resto de la mancha urbana. La dependencia a una sola vialidad primaria para las salidas y entradas con el consiguiente congestionamiento refuerza este escenario. Los grandes conjuntos cerrados de nivel popular del suroriente y surponiente de la ciudad no sólo se ven limitados por las distancias cada vez mayores con los lugares de trabajo, estudio y recreación, sino también por la ausencia de equipamientos comerciales y de servicios.

El 55.5\% de los fraccionamientos cerrados detectados se encuentra enlazado a vialidades primarias, encontrándose entre ellos la mayoría de los grandes desarrollos de interés social (cuadro 2). Sólo los fraccionamientos exclusivos Real del Mar, Brisas del Mar y San Marino, ubicados sobre la carretera escénica a Ensenada, se enlazan a una vialidad primaria, pero las dimensiones de estos sitios son pequeñas, y aprovechan el paisaje cercano al mar y la carretera para aislar y jugar con la exclusividad. El 41.6\% de los fraccionamientos cerrados se encuentra enlazado a vialidades secundarias, destacándose que la mayoría de estos fraccionamientos son de nivel medio y alto y se ubican en los sectores más exclusivos de Tijuana, como Playas de Tijuana y el entorno de Agua Caliente en la parte central de la ciudad. En el sector de Agua Caliente los espacios cerrados de más reciente construcción son de tamaño reducido y se establecen sobre suelo intersticial. La topografía accidentada del sector sirve para exaltar el paisaje jugando con los desniveles de terreno. Los fraccionamientos cerrados

Cuadro 2.

Tipo de conexión vial del fraccionamiento cerrado

\begin{tabular}{lrrrrrrrr}
\hline \multicolumn{1}{c}{ Tipo } & \multicolumn{2}{c}{$\begin{array}{c}\text { Vialidad } \\
\text { primaria }\end{array}$} & \multicolumn{2}{c}{$\begin{array}{c}\text { Vialidad } \\
\text { colectora }\end{array}$} & \multicolumn{2}{c}{$\begin{array}{c}\text { Vialidad } \\
\text { secundaria }\end{array}$} & \multicolumn{2}{c}{ Total } \\
Ciudad & Abs. & $\%$ & Abs. & $\%$ & Abs. & $\%$ & Abs. & $\%$ \\
\hline Tijuana & 40 & 55.5 & 2 & 2.8 & 30 & 41.7 & 72 & 100 \\
Nogales & 5 & 45.4 & 2 & 18.2 & 4 & 36.4 & 11 & 100 \\
Ciudad Juárez & 15 & 41.7 & 10 & 27.8 & 11 & 30.5 & 36 & 100 \\
Total & 60 & 50.4 & 14 & 11.8 & 45 & 37.8 & 119 & 100 \\
\hline
\end{tabular}

Fuente: Elaboración propia. 
contribuyen a densificar la zona y no necesariamente requieren de vialidades primarias, pues el sector de Agua Caliente es uno de los más caros e inaccesibles de la ciudad, lo cual contribuye a inhibir el tráfico ajeno. El entorno de Agua Caliente mantiene cercanía con centros comerciales, franquicias norteamericanas, colegios particulares y servicios de entretenimiento. Además, su topografía accidentada contribuye a la inaccesibilidad de los fraccionamientos cerrados.

En general, Tijuana es una ciudad condicionada por su topografía, rasgo que por sí mismo incide para dificultar la construcción de una ciudad accesible y legible (cuadro 3). Como ejemplo, $65.2 \%$ de los fraccionamientos cerrados detectados tiene colindancia con suelo intersticial conformado en su mayoría por cañadas, taludes de cerro, cortes de tierra para paliar la amenaza de derrumbe y cauces de arroyo. Sin embargo, los fraccionamientos cerrados contribuyen poco a la tarea de crear un espacio urbano accesible y legible, por el contrario presionan para reforzar los mecanismos de separación y de exclusión.

En los recorridos de campo se detectó que $37.5 \%$ de los fraccionamientos tiene colindancia con colonias populares o conjuntos abiertos de interés social, generalmente preexistentes. Con el fin de resguardar y proteger la seguridad o el valor de la propiedad fue necesario establecer barreras físicas para separar las áreas cerradas de las abier-

\section{Cuadro 3.}

Colindancias del fraccionamiento cerrado

\begin{tabular}{lrrrrrrrr} 
& \multicolumn{2}{c}{$\begin{array}{l}\text { Suelo } \\
\text { intersticial }\end{array}$} & \multicolumn{2}{l}{$\begin{array}{l}\text { Fraccio- } \\
\text { namientos } \\
\text { abiertos }\end{array}$} & \multicolumn{2}{l}{$\begin{array}{l}\text { Fraccio- } \\
\text { namientos } \\
\text { cerrados }\end{array}$} & \multicolumn{2}{l}{$\begin{array}{l}\text { Otro tipo } \\
\text { de suelo } \\
\text { urbano }\end{array}$} \\
& Abs. & $\%$ & Abs. & $\%$ & Abs. & $\%$ & Abs. & $\%$ \\
\hline $\begin{array}{l}\text { Tijuana } \\
\text { Nogales }\end{array}$ & 47 & 65.3 & 27 & 37.5 & 25 & 34.7 & 25 & 34.7 \\
Ciudad Juárez & 8 & 72.7 & 10 & 90.9 & 2 & 18.2 & 11 & 100 \\
& 23 & 63.9 & 9 & 25.0 & 24 & 66.7 & 25 & 69.4 \\
\hline
\end{tabular}

* Maquiladoras, área comercial.

Fuente: Elaboración propia. 
tas, como sucede en el Fraccionamiento Californias ubicado en la colonia Libertad. El fraccionamiento de nivel medio-alto Vistas de Otay también ejemplifica el proceso de separación por su ubicación en medio del populoso sector de la colonia Fovisste conformado por torres de departamentos y fraccionamientos construidos por el Infonavit.

Otro elemento importante que abona en la construcción de un escenario urbano inaccesible es que $34.7 \%$ de los fraccionamientos tiene colindancia con otros conjuntos cerrados. Los fraccionamientos cerrados de Agua Caliente presentan esta particularidad; la exclusividad del sector no es suficiente para limitar la disposición de barreras físicas, por el contrario, se robustece la fragmentación con fines de exaltar la individualidad de los espacios. Un ejemplo diferente son los sectores El Florido y El Refugio al suroriente de la ciudad, donde la proliferación de fraccionamientos cerrados de interés social es abrumante. En el sector de El Florido se encuentran los fraccionamientos cerrados Cañadas del Florido I y II, Paseo del Florido y Hacienda Casa Grande, cada uno de ellos conformado por miles de viviendas. Estos fraccionamientos se encuentran incomunicados entre sí a pesar de ser contiguos, mantener el mismo diseño urbano de privadas en forma de peine y estar orientados a trabajadores de las maquiladoras y de los servicios. El 39.7\% de estos fraccionamientos de interés social tiene colindancia con parques industriales de maquiladoras.

En el caso de Nogales se detectaron 11 fraccionamientos cerrados, de los cuales tres se encuentran en fase de construcción. A diferencia de Tijuana y Ciudad Juárez, Nogales es una ciudad pequeña aunque con una tasa de crecimiento alto, rasgo propicio para que los problemas urbanos tiendan a agravarse. Entre esos problemas es significativa la cantidad de invasiones urbanas ubicadas en sitios inadecuados, por lo accidentado del terreno, y aislados de la ciudad, con serias carencias de equipamientos y deficiente dotación de servicios básicos. Entre otros problemas se encuentra el anárquico sistema urbano de la ciudad, conformado por vialidades, equipamientos, infraestructura, parques industriales y áreas residenciales que contribuyen a crear un escenario difícilmente accesible y legible. La topografía donde se asienta la ciudad es sumamente abrupta, con pendientes mayores a 30 gra- 
dos. Los atributos del suelo propician que las zonas aptas para urbanizar sean muy limitadas, y la posibilidad de establecer elementos para una adecuada planeación se ven obstaculizadas por la topografía.

El caótico sistema de vialidades de la ciudad, ayudado por lo escarpado del terreno, dificulta saber cuándo estamos ante una vialidad primaria o secundaria, sin embargo, para los propósitos de la investigación se logró establecer que $45.5 \%$ de los fraccionamientos cerrados se encuentra sobre una vialidad primaria y $54.5 \%$ sobre vialidades más accesorias que secundarias. A pesar de su ubicación sobre vialidades primarias o secundarias, los fraccionamientos cerrados son inaccesibles no sólo por los muros y accesos controlados sino también por el emplazamiento en sitios accidentados o en huecos de colonias populares, resultando invisibles a los ojos de la ciudad. El 72.7\% de los fraccionamientos cerrados tiene colindancia con suelo intersticial consistente en cañadas, taludes de cerro y cortes de tierra para evitar derrumbes. Además, los 11 fraccionamientos cerrados tienen como vecinos a las maquiladoras, destacándose el caso del fraccionamiento Casa Blanca de nivel medio-alto, emplazado a un costado del parque industrial Nuevo Nogales II, aislado completamente de la mancha urbana e inaccesible si no es recorriendo las vialidades del parque industrial.

En Nogales los fraccionamientos cerrados se ubican de manera periférica y lejana del núcleo central de la ciudad, sin áreas comerciales o recreativas cercanas; están orientados a la incipiente clase media y son, en su mayoría, asentamientos nuevos (el más antiguo data de inicios de la década de los noventa). Los conjuntos cerrados de Nogales son pequeños y de difícil acceso, varios de ellos resultan invisibles por encontrarse en medio de barrios populares o por lo abrupto del terreno, llenando intersticios dejados por las inmobiliarias. Sólo el fraccionamiento Santa Lucía, al suroriente de la ciudad, puede jactarse de estar ubicado sobre un suelo con una pendiente ligera, ligado a una vialidad importante que conecta hacia la carretera internacional y hacia el centro de la ciudad (figura 2). En general, los fraccionamientos cerrados presentes en Nogales no tienen un fuerte impacto en el escenario urbano dado su reducido número, más aún cuando, a diferencia de lo observado en Tijuana, los grandes fraccionamiento de interés 
Figura 2.

Ubicación de los fraccionamientos cerrados en Nogales

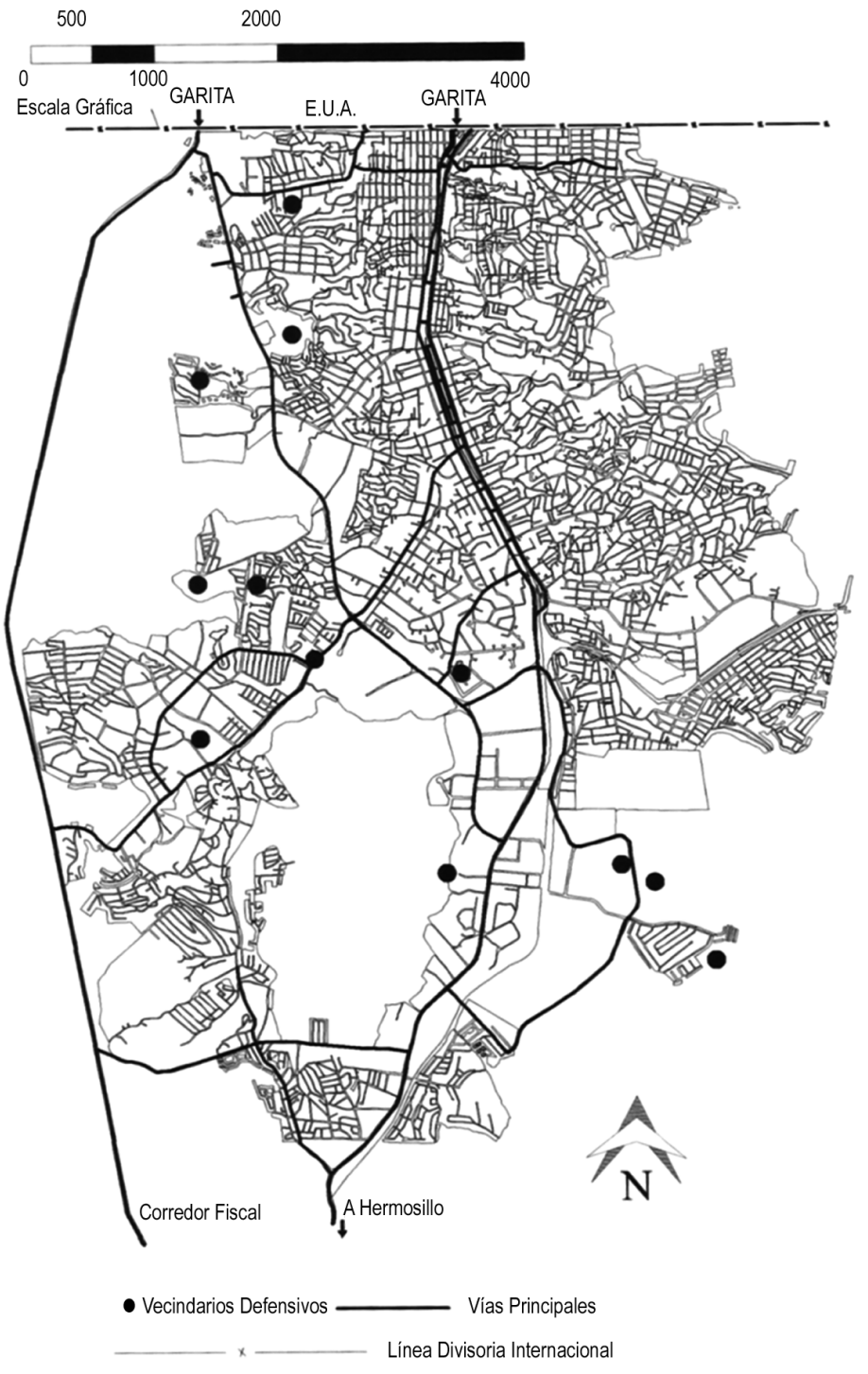

Fuente: Elaboración propia con base en las fichas de registro. 
social todavía son abiertos; sin embargo, es la única opción para la clase media deseante de espacios tranquilos y seguros.

En Ciudad Juárez se detectaron 36 fraccionamientos cerrados, de los cuales $36.1 \%$ se encontraban inconclusos por estar en fase de construcción. Se observa que los fraccionamientos cerrados se ubican en la parte oriente de la ciudad, sobre campos agrícolas localizados en una franja que corre de norte a sur contigua al Río Bravo. Es un gran espacio de superficie plana atravesado por acequias, antiguas haciendas y restos de pequeños asentamientos rurales (figura 3).

Figura 3.

Ubicación de fraccionamientos cerrados en Ciudad Juárez

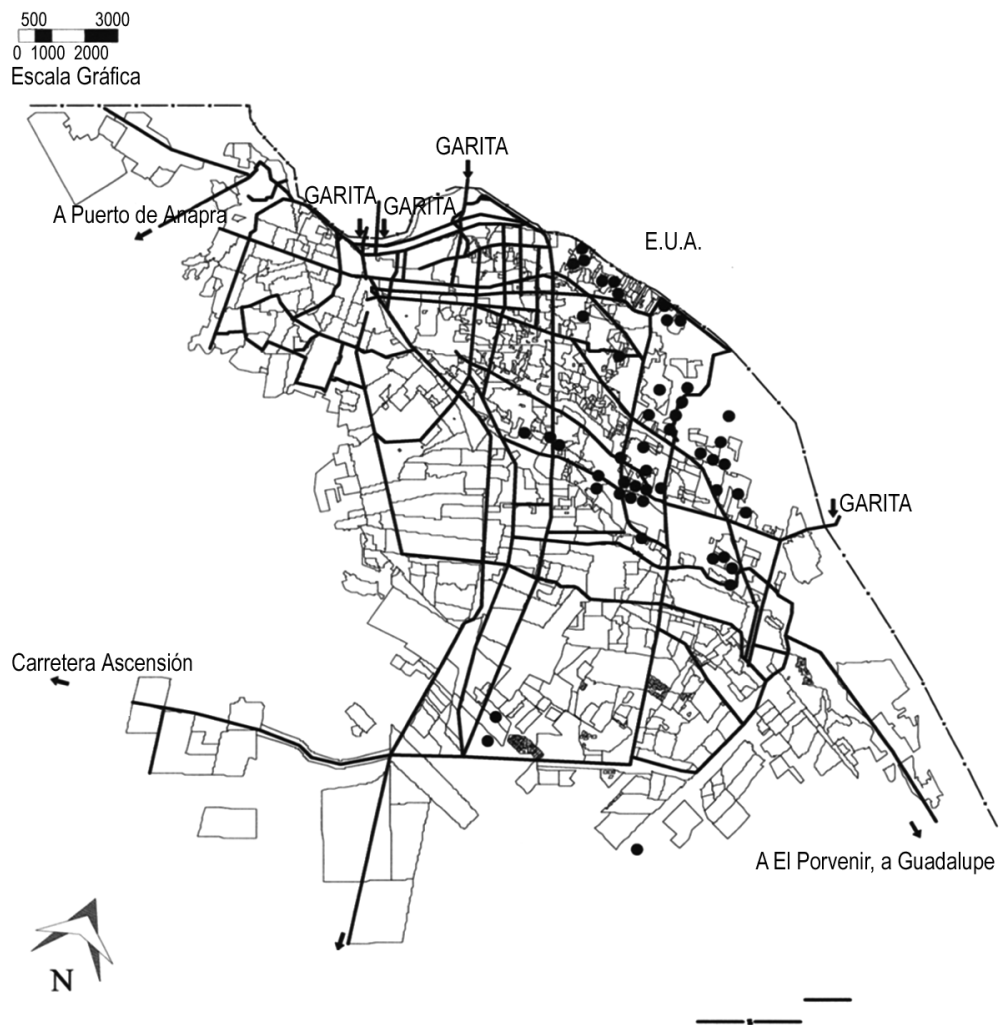

Fuente: Elaboración propia con base en las fichas de registo. 
El 41.6\% de los fraccionamientos cerrados detectados se ubica sobre vialidades primarias, como los bulevares Gómez Morín, Paseo de la Victoria, 4 Siglos, Francisco Villarreal y Ejército Nacional. El 27.7\% se encuentra sobre vialidades colectoras que desembocan en las vialidades antes mencionadas. El 30.5\% está en vialidades secundarias. El trazado viario recién modernizado del sector oriente de la ciudad permite una conexión rápida de los fraccionamientos cerrados con el resto de la mancha urbana y con los pasos fronterizos de Zaragoza o de Las Américas. La mayoría son pequeños, no sobrepasan las 100 viviendas en promedio y están orientados a las clases media y alta. Los fraccionamientos que rompen esa regla son los casos de Colonial del Valle y Villas del Real, este último de la empresa Urbi, la misma que construyó los grandes complejos residenciales de interés social de Tijuana. Ubicado al sur de la ciudad, rodeado por dos parques industriales destinados a las maquiladoras, es un espacio con construcciones de interés social y popular que ronda las mil viviendas, con diseño urbano basado en pequeñas privadas conformadas por 60 casas que desembocan en una vialidad colectora. Este espacio es el único que rompe con la tendencia de ubicar los fraccionamientos cerrados al oriente de la ciudad, y sus residentes son, en su mayoría, trabajadores de maquiladoras y empleados del sector servicios.

Por su parte, el fraccionamiento Colonial del Valle llama la atención no sólo por establecerse al oriente de la ciudad sobre antiguos campos agrícolas, sino porque es un fraccionamiento conformado por 400 viviendas que combinan secciones de interés social y nivel medio, cada una de ellas separada de la otra por muros de protección de manera que no se interactúan los residentes de una y otra condición socioeconómica. Los resabios de la actividad agrícola fueron aprovechados por la inmobiliaria para presentar un discurso que armoniza naturaleza y calidad de vida; por ejemplo, las cortinas de árboles utilizadas antiguamente para proteger los cultivos de los vientos se mantienen como parte de la ambientación ecológica y de las abundantes áreas verde. En la misma circunstancia se encuentra el resto de los fraccionamientos cerrados contiguos, como Privadas Miraloma, Las Estancias, Quinta Real y San Pablo. 
En Ciudad Juárez los fraccionamientos cerrados se ven beneficiados por el equipamiento y la infraestructura urbana existente. Ubicarse a lo largo o cerca de vialidades importantes les facilita la conexión rápida con la ciudad, aunque no necesariamente se fomenta la accesibilidad ni se favorece la legibilidad urbana. El diseño urbano del fraccionamiento cerrado generalmente consiste en conjuntos de menos de 100 viviendas, y se basa en un circuito que rodea un parque central y está protegido por altos muros perimetrales de cantera. Se emplazan de manera solitaria en medio de la zona agrícola, y los altos muros les confieren una imagen de fortaleza, guardando similitud con los antiguos fuertes utilizados por españoles y mexicanos en el norte del país para defenderse de los indios. Esa configuración del fraccionamiento cerrado no favorece la accesibilidad urbana porque se privilegia más la fragmentación del espacio que la integración. En todo caso, la legibilidad urbana construida indica un mosaico de fragmentos adyacentes pero poco imbricados entre sí.

Esta visión fragmentada de la ciudad puede cuantificarse observando que de los 36 fraccionamientos detectados, $63.8 \%$ mantiene colindancia con suelo intersticial conformado en su mayoría por suelo agrícola, áreas baldías sin urbanizar y en menor medida maquiladoras. Otro dato importante que corrobora el escenario urbano poco accesible en formación es que $66.6 \%$ mantiene colindancia con otros fraccionamientos cerrados o al menos guarda contigüidad por encontrarse separados sólo por suelo agrícola.

Por miedo a la violencia o por búsqueda de prestigio y distinción, los residentes de nivel socioeconómico medio y alto eligen vivir en el fraccionamiento cerrado sin importar si los espacios se integran o no a la estructura urbana. Los grupos sociales más pudientes tienden a establecerse en los sectores más exclusivos, buscando reconocimiento y mayor estatus social por medio del espacio físico, sin interesar si se contribuye a extender el aislamiento con respecto a otros grupos sociales o si se está cooperando a la creciente inaccesibilidad que los muros establecen en las ciudades. Bajo esas condiciones, la legibilidad urbana sólo puede operar en los espacios interiores de los fraccionamientos por la particularidad de los diseños urbanos, la calidad de las construcciones y la prodigalidad de los espacios verdes; es 
sólo dentro de los fraccionamientos donde es posible reconocer las partes que dan coherencia o legibilidad al espacio urbano.

Cosa muy diferente ocurre en los fraccionamientos cerrados populares, donde la seguridad y el nivel de vida prometidos son sólo un recurso retórico de las inmobiliarias o de los mensajes publicitarios seductores que presentan imágenes de familias felices, niños jugando en las calles y vecinos cooperando entre sí para cuidar sus espacios. La realidad es muy distinta, pues esos espacios están condenados a la precariedad por la mala construcción de las viviendas, por el marco legal que faculta a las constructoras para emplear normas mínimas en la dimensiones de las mismas (a costa de inadecuadas condiciones de habitabilidad) y por el régimen de condominio que impide modificar o ampliar las construcciones de acuerdo al tamaño de la familia o al deseo estético de los residentes. La naturaleza masiva del fraccionamiento cerrado de interés social recrea paisajes más abigarrados que legibles.

Retomando a Quadri de la Torre (2005), los fraccionamientos cerrados representan bastante bien el proceso de construcción de viviendas sin ciudad. Los espacios cerrados se difuman en la superficie de las ciudades fronterizas sin integrarse a ella ni formar un conjunto que confiera legibilidad; sólo dibujan una sucesión de islotes de felicidad controlada, estatus y calidad de vida, frente a espacios amenazados por su gran tamaño. La seguridad sigue siendo un pretexto para cerrar las ciudades, el fraccionamiento cerrado fomenta la percepción de los espacios abiertos como amenazantes y los muros con casetas de acceso regulado representan la certidumbre y la tranquilidad.

\section{Seguridad y vigilancia}

Las ciudades fronterizas son afectadas por altos niveles de inseguridad, en ellas predomina el narcotráfico de las grandes mafias nacionales, los asesinatos, el narcomenudeo de esquina, la violencia intrafamiliar y la delincuencia común, rubro en el cual destacan el robo a casa-habitación y el asalto armado. El Estado y sus diversos órdenes de gobierno resultan insuficientes para enfrentar la inseguridad, evitar la impunidad y aplicar la ley. Si agregamos los niveles de 
desigualdad social existentes tanto en el país como en las ciudades fronterizas encontramos el caldo de cultivo que explica la búsqueda de remansos de tranquilidad y seguridad: el fraccionamiento cerrado.

Los fraccionamientos cerrados basan la construcción de una imagen de seguridad en los muros que rodean el conjunto urbano, la caseta de acceso enmarcada por una arcada monumental y la presencia de guardias privados. Se atribuye su éxito a la posibilidad de proteger a sus habitantes de la inseguridad y de la delincuencia que prevalecen en las ciudades. Las medidas de seguridad instrumentadas varían, pero básicamente descansan en la visibilidad de los elementos de vigilancia para amedrentar o inhibir a los delincuentes. En las visitas realizadas a las ciudades fronterizas de Tijuana, Nogales y Ciudad Juárez (cuadro 4), se hizo un recuento de las medidas de seguridad establecidas en los fraccionamientos cerrados y se encontró que éstas también son utilizadas para expresar distinción social.

En Tijuana, 93\% de los fraccionamientos posee caseta de vigilancia en la entrada principal del conjunto, recurso muy socorrido para regular el acceso de propios y extraños. Pero la caseta dispuesta en el

Cuadro 4.

Medidas de seguridad en los fraccionamientos cerrados, 2004-2005

\begin{tabular}{|c|c|c|c|c|c|c|}
\hline \multirow{2}{*}{$\begin{array}{l}\text { Medidas } \\
\text { de seguridad }\end{array}$} & \multicolumn{2}{|c|}{ Tijuana } & \multicolumn{2}{|c|}{ Nogales } & \multicolumn{2}{|c|}{ Ciudad Juárez } \\
\hline & Abs. & $\%$ & Abs. & $\%$ & Abs. & $\%$ \\
\hline Caseta & 67 & 93.0 & 10 & 90.9 & 36 & 100 \\
\hline Guardias & 52 & 72.2 & 9 & 81.8 & 35 & 97.2 \\
\hline Pluma manual & 22 & 30.5 & 6 & 54.5 & 6 & 16.7 \\
\hline Cámara/cc & 10 & 13.9 & 0 & 00.0 & 2 & 5.5 \\
\hline Reja control & & & & & & \\
\hline electrónico & 22 & 30.5 & 0 & 00.0 & 30 & 83.3 \\
\hline Reja manual & 32 & 44.4 & 4 & 36.4 & 5 & 13.9 \\
\hline Estacionamiento & & & & & & \\
\hline $\mathrm{p} /$ visitantes & 22 & 30.5 & 4 & 36.4 & 8 & 22.2 \\
\hline
\end{tabular}

Fuente: Elaboración propia. 
acceso no sólo cumple el propósito de regular la entrada, sino también forma parte del paisaje urbano del conjunto pues mantiene un estilo arquitectónico acorde a la simbología evocada en el nombre del espacio y la arquitectura mexicana o californiana utilizada en los diseños de las viviendas. La caseta de acceso suele estar reforzada con plumas, rejas de control manual o sistemas más sofisticados como las rejas de control electrónico. El 30.5\% cuenta con caseta con pluma en el control de acceso, otro $30.5 \%$ de los fraccionamientos tiene caseta y reja controlada electrónicamente, y $44.4 \%$ mantiene la reja de control manual como el recurso de seguridad más utilizado. El 13.8\% de los fraccionamientos recurre también a cámaras de circuito cerrado para vigilar los perímetros, el acceso y las áreas comunes. Los niveles de sofisticación técnica para vigilar la seguridad en los fraccionamientos cerrados dependen del nivel socioeconómico de sus residentes, de modo que los controles electrónicos en los portones de acceso o los sistemas de circuito cerrado son empleados en fraccionamientos de nivel medio-alto y alto. En los fraccionamientos cerrados de interés social y en los de nivel medio son más requeridas las rejas y las plumas pues aparte de ser más económicas para los residentes son más fáciles de usar por los guardias.

Existen fraccionamientos donde el diseño urbano en cul de sac compuesto por privadas mantiene en cada uno de sus accesos portones electrónicos dirigidos a control remoto por los vecinos, reservando a los guardias privados sólo para todo el conjunto. Fraccionamientos medios-altos como Residencial de Agua Caliente, Jardines del Lago y Vistas de Otay son conjuntos diseñados en privadas con portón electrónico. En el fraccionamiento Medina Mediterráneo las medidas de seguridad son extremas, pues existen guardias, cámaras con circuito cerrado, bardas perimetrales iluminadas, caseta de acceso con portón electrónico y cada vivienda refuerza su seguridad con sistemas de alarma, ventanas blindadas y cochera con puerta eléctrica.

Caseta de vigilancia, rejas y plumas no son los únicos recursos de seguridad utilizados en los fraccionamientos. El 72.2\% de ellos cuenta con guardias privados las 24 horas del día, tanto en la caseta como haciendo recorridos constantes. De nueva cuenta, el nivel social y económico de los residentes determina el profesionalismo de los guar- 
dias privados. Los fraccionamientos de nivel alto y algunos de nivel medio contratan guardias de compañías dedicadas a la seguridad supuestamente mejor adiestrados y capacitados, con equipo de radiocomunicación y vehículos. En la mayoría de los fraccionamientos medios y de interés social el uso de guardias mal entrenados, peor pagados y sin prestaciones sociales es el mejor de los casos; en el peor se trata de guardias improvisados por los mismos vecinos. Se detectó que $22.2 \%$ de los fraccionamientos de Tijuana están abiertos durante el día sin ningún tipo de control en el acceso, aun cuando cuentan con guardias privados.

Otra medida de seguridad característica del fraccionamiento cerrado son los muros de protección perimetrales (cuadro 5). Para la ciudad de Tijuana existen diversas formas de delimitar los perímetros, que generalmente combinan bardas, cercos de malla ciclónica y, dada la topografía accidentada de la ciudad, taludes de cerro que sirven como barrera de protección. El $69.4 \%$ de los fraccionamientos utiliza las bardas, $44.4 \%$ cuenta con cerco de malla ciclónica y en $31.9 \%$ el talud del cerro o una cañada funciona como límite. Se detectaron conjuntos en los que la barda metálica de la línea fronteriza entre México y Estados Unidos funciona como límite del fraccionamiento cerrado, entre ellos los fraccionamientos La Isla y Terrazas de Mendoza en Playas de Tijuana. También en Playas de Tijuana el mar funciona como parte de los límites, como sucede en La Perla y Playa Blanca, aunque aquí el mar es parte del manejo paisajístico del conjunto más que una barrera de protección.

\section{Cuadro 5.}

Delimitación física de los fraccionamientos cerrados

\begin{tabular}{lrrrrrr}
\hline & Ciudad & \multicolumn{2}{c}{ Tijuana } & \multicolumn{2}{c}{ Nogales } & \multicolumn{2}{c}{ Ciudad Juárez } \\
Tipo & Abs. & $\%$ & Abs. & $\%$ & Abs. & $\%$ \\
\hline Barda & 50 & 69.4 & 7 & 63.6 & 36 & 100 \\
Cerco & 32 & 44.4 & 6 & 54.5 & 0 & 0 \\
Taludes & 23 & 31.5 & 6 & 54.5 & 0 & 0 \\
Calle & 3 & 4.2 & 0 & 00.0 & 0 & 0 \\
\hline
\end{tabular}

Fuente: Elaboración propia. 
Muros, casetas de acceso y guardias privados no son suficientes para vivir con tranquilidad y seguridad, por lo que las viviendas del fraccionamiento cerrado tienen sus propias medidas de protección. La percepción del miedo real o imaginado se expresa con los refuerzos al interior de la vivienda. En $16.6 \%$ de los fraccionamientos los residentes erigen altas bardas laterales, no sólo para delimitar el espacio con respecto a los vecinos, sino también para reforzar la protección. En algunos casos, las bardas disponen incluso de alambre de púas. El $68 \%$ de los fraccionamientos recurre a la utilización de rejas en ventanas, puertas y parte frontal de la vivienda. En $26.3 \%$ de los fraccionamientos se detectó el uso generalizado de alarmas en las viviendas. El precio de la tranquilidad es el enjaulamiento de las viviendas.

Comparado con Tijuana, Nogales tiene pocos fraccionamientos cerrados, pero a pesar del reducido número las medidas de seguridad y vigilancia para vivir en tranquilidad son semejantes. De los 11 fraccionamientos cerrados detectados, $90.9 \%$ tiene caseta de vigilancia en el acceso principal. Algunos de ellos, como Santa Lucía, Retorno del Sol, Real del Arco y La Riviera fueron cerrados por los vecinos una vez finalizado el proceso de venta por parte de la inmobiliaria, y puesto que las casetas de vigilancia no estaban dentro del concepto ofrecido tienen un diseño más austero, sin estilo arquitectónico definido y sujeto a las economías de los vecinos. Solamente en los residenciales medio-altos de Casablanca y Kennedy las casetas de vigilancia son parte del paisaje urbano, cumpliendo la doble función de controlar el acceso y expresar distinción social.

El $90.9 \%$ de los fraccionamientos cerrados goza de vigilancia con guardias privados las 24 horas, y en los restantes sólo hay vigilancia durante el día. Las casetas de vigilancia de los fraccionamientos están reforzadas en $54.5 \%$ de ellos con pluma, y $36.3 \%$ con reja manual. El terreno accidentado de la ciudad condiciona que los límites de los fraccionamientos cerrados combinen muros, cercos y talud de cerro. De ese modo, $63.6 \%$ de los fraccionamientos tiene bardas, $54.5 \%$ cercos de alambre y $54.5 \%$ tiene como perímetro el talud del cerro o cañada. Los refuerzos de protección al interior de las viviendas más utilizadas son las rejas, pues el 100\% de los fraccionamientos dispo- 
nen de ellas en puertas y ventanas, en tal cantidad que en algunos casos las partes frontales de las viviendas se convierten en verdaderas jaulas, sólo en tres fraccionamientos existe un uso generalizado de alarmas; y en cuatro de ellos la tendencia a individualizar el espacio y a proteger la propiedad ha llevado a los vecinos a levantar altas bardas en los patios posteriores y al frente de las casas.

En Ciudad Juárez las medidas de seguridad dispuestas en los fraccionamientos cerrados son más efectivas que en las otras dos ciudades estudiadas. En Tijuana las autoridades municipales consideran la calle donde se ubican las casetas de vigilancia como públicas, de modo que las restricciones de acceso no son tan estrictas. En Nogales ocurre algo semejante, y por tanto en Ciudad Juárez el endurecimiento de las barreras es más marcado. Un indicador del endurecimiento de las restricciones fueron las dificultades que encontramos para ingresar en los conjuntos cerrados y la amedrentación recibida por los guardias privados; en la mayoría de los fraccionamientos nos fue negado el acceso.

En Ciudad Juárez, el 100\% de los fraccionamientos cerrados detectados cuenta con caseta de vigilancia en el acceso principal. La caseta es parte del diseño urbano del conjunto, y la promoción de los fraccionamientos ofrece dentro del paquete de venta la seguridad representada por las restricciones al acceso. De ese modo, las casetas de acceso no sólo sirven para proporcionar seguridad, pues también proveen prestigio social a los moradores al incorporar estilos arquitectónicos de acuerdo al emblema o nombre del conjunto y se aderezan en ocasiones con arcadas de tipo monumental. La caseta de acceso refuerza la seguridad y la efectividad de la vigilancia con tecnología, 83.3\% de los fraccionamientos dispone de rejas de control electrónico, en 5.5\% existen cámaras con circuito cerrado y sólo 16.6\% utiliza la pluma o reja de control manual. En ningún fraccionamiento existe acceso peatonal. En $97.2 \%$ de los fraccionamientos existe vigilancia privada las 24 horas del día con guardias contratados en compañías de seguridad. Los fraccionamientos cerrados de nivel alto y medioalto cuentan con guardias privados uniformados, con equipo de radiocomunicación y vehículos. Sólo en el fraccionamiento Villas del Rey, de interés social, se pudo constatar la presencia de guardias im- 
provisados contratados por los propios vecinos, aunque parte de las privadas no tienen servicio de vigilancia y en algunos casos los portones de acceso no funcionan o no existen. En Ciudad Juárez es significativa la presencia de guardias privados en la vigilancia de los fraccionamientos, aunque eso no garantiza la efectividad del servicio debido a la informalidad legal y profesional de las compañías de seguridad privada que existen en la ciudad.

Hemos comentado que los fraccionamientos cerrados de Ciudad Juárez no son de grandes dimensiones, y que no concentran gran volumen de población ni alta densidad habitacional. El diseño urbano basado en circuitos alrededor de un área central favorece el control de la seguridad de los espacios al fomentar la visibilidad y accesibilidad interior, y esa cualidad favorece también el que no se generalice el uso de bardas para delimitar el espacio entre las viviendas. Las fachadas y los patios frontales de las viviendas están en la mayoría de los casos libres de barreras que individualicen el espacio, como cocheras eléctricas y enrejados perimetrales, aunque $69.4 \%$ de los fraccionamientos dispone de rejas de protección en puertas y ventanas, y en 38.8\% existe un uso extendido de alarmas en las viviendas.

Su tamaño pequeño y la ubicación aislada del entorno rodeado de campos agrícolas ayuda a que el fraccionamiento cerrado asuma una forma defensiva, privilegiando el uso de altas bardas de cantera rematadas en ocasiones con enrejados o pilastras ornamentadas. El 100\% de los fraccionamientos detectados mantiene muros de piedra que cumplen un doble propósito: por un lado, proteger y ocultar los paisajes interiores, y por otro, conferir de distinción social a los conjuntos $\mathrm{y}$ a sus moradores.

La seguridad parece ser una de las condiciones que hace posible la aparición y expansión del fraccionamiento cerrado en las ciudades de Tijuana, Nogales y Ciudad Juárez, sin embargo, no existen estadísticas oficiales que refieran un impacto positivo de la instauración de barreras físicas en la seguridad. La disminución de delitos en esos espacios no puede ser corroborada, sólo quedan las percepciones de los propios residentes quienes consideran sus espacios seguros aunque posean referencias o conocimiento de hechos delictivos ocurridos en el interior. El otro tema importante desprendido de la seguridad 
del fraccionamiento cerrado es el uso de guardias privados. La información disponible refiere su utilización generalizada como recurso de vigilancia, pero también da cuenta de la informalidad bajo la cual funcionan las compañías privadas, pues salvo casos excepcionales impera el escaso adiestramiento y el limitado nivel de profesionalismo en los guardias. Igualmente se desprende del asunto de la seguridad en el fraccionamiento cerrado una relación marcada entre el endurecimiento de la vigilancia y el nivel socioeconómico de sus habitantes; así, entre más exclusividad social contenga el conjunto urbano, mayor es la efectividad de las medidas materiales de protección.

\section{Sustentabilidad urbana}

El concepto de sustentabilidad urbana remite a la capacidad de las ciudades para contribuir a la realización social, económica y material de sus habitantes. Implica un uso eficiente de los recursos materiales y ambientales, de accesibilidad a los bienes y servicios urbanos, y la equidad y participación social. Retomando a Carrasco (2005) es posible ubicar el fenómeno de los fraccionamientos cerrados en relación con sus contribuciones a la sustentabilidad en cuanto al diseño urbano, el diseño arquitectónico y la integración social al contexto urbano. Los fraccionamientos cerrados de las ciudades fronterizas no precisamente contribuyen a la realización de esas condiciones, o en todo caso lo hacen parcialmente en algunos aspectos.

En Tijuana el fraccionamiento cerrado facilita la redensificación urbana sólo en los casos de fraccionamientos de nivel medio y alto ubicados en los sectores exclusivos de Agua Caliente y de Playas de Tijuana; estos fraccionamientos ocupan pequeños fragmentos de suelo intersticial que el desarrollo urbano presentado en el sector no había ocupado. Por el contrario, $65.2 \%$ de los fraccionamientos detectados se ubica en suelo periurbano, alejados de la mancha urbana y con limitaciones físicas para conectarse a la ciudad. La expansión de los fraccionamientos cerrados en la periferia de la ciudad obliga a privilegiar el transporte privado sobre el público, tanto por el acrecentado individualismo de la población por razones culturales y sociales como por las deficiencias notorias del transporte público. Por otro lado, la 
expansión del fraccionamiento cerrado en la periferia tiene un costo importante por las inversiones realizadas para llevar a sitios cada vez más lejanos servicios e infraestructura urbana, costo amortiguado por las inmobiliarias mediante una mayor densidad habitacional y viviendas cada vez más pequeñas y de menor calidad.

La expansión del fraccionamiento cerrado en la periferia da forma a una ciudad cada vez más extensa. Sin embargo, la salida a la periferia y la redensificación operada en ciertos lugares no significa un crecimiento vertical para optimizar el suelo urbano (cuadro 6). El 81.9\% de los fraccionamientos sólo cuenta con viviendas unifamiliares, $13.8 \%$ de los fraccionamientos tiene edificios de departamentos y sólo $4.2 \%$ combina viviendas unifamiliares con multifamiliares. Al parecer, en Tijuana no son bien aceptadas por la población las edificaciones de tipo vertical. A decir de un promotor del fraccionamiento Campestre Morúa, ubicado sobre el cauce del río Alamar, la inmobiliaria ha tenido dificultades para vender los departamentos a pesar de que éstos tienen un menor costo y mayores dimensiones que una vivienda horizontal.

La superficie de Tijuana, compuesta por lomeríos y cañadas de grandes pendientes, obliga a las inmobiliarias a realizar grandes trabajos para emparejar el suelo o hacerlo más apropiado para la construcción de viviendas. Sin embargo, la condición topográfica sigue siendo una condición que dificulta la creación de asentamientos pues implica lidiar con cauces de arroyo y suelos blandos muy permeables y poco

Cuadro 6.

Tipos de fraccionamientos cerrados

\begin{tabular}{lcrrrrrr}
\hline \multirow{2}{*}{ Vivienda } & \multicolumn{3}{c}{ Unifamiliar } & \multicolumn{3}{c}{ Multifamiliar } & \multicolumn{2}{c}{ Mixto } & \multicolumn{2}{c}{ Total } \\
& Abs. & $\%$ & Abs. & $\%$ & Abs. & $\%$ & Abs. \\
\hline Tijuanad & 59 & 81.9 & 10 & 13.8 & 3 & 4.2 & 72 \\
Nogales & 11 & 100 & 0 & 0 & 0 & 0 & 11 \\
Ciudad Juárez & 36 & 100 & 0 & 0 & 0 & 0 & 36 \\
Total & 106 & 89.1 & 10 & 8.4 & 3 & 2.5 & 119 \\
\hline
\end{tabular}

Fuente: Elaboración propia. 
consolidados. A pesar de las condiciones descritas, 36.1\% de los fraccionamientos se ubica sobre pendientes ligeras, $45.8 \%$ sobre pendientes muy pronunciadas, con urbanizaciones en forma de terrazas y con altos muros de contención, y sólo $18 \%$ sobre suelo plano. Pero la construcción de viviendas sobre suelo poco apto y con topografía conformada por laderas y cañadas incrementa las condiciones de riesgo para la población establecida en los fraccionamientos (cuadro 7). El $48.6 \%$ de los fraccionamientos cerrados se encuentra en situación de riesgo, siendo vulnerables a derrumbes por la erosión de taludes, la inundación por taponamiento de arroyos y los movimientos del suelo poco estable. Además, Tijuana se encuentra en una zona sísmica, por lo cual la situación de riesgo es mayor.

Un elemento del fraccionamiento cerrado que no contribuye a la sustentabilidad urbana son las limitaciones para mantener usos mixtos del suelo. El régimen de condominio generalizado en el escenario urbano tijuanense restringe la posibilidad de utilizar el suelo de forma distinta a la residencial. Sólo $6.9 \%$ de los fraccionamientos cerrados cuenta con áreas comerciales y de servicios en su interior y se trata de grandes conjuntos urbanos como Santa Fe, Cañadas del Refugio I y II y Las Villas en sus cuatro secciones. La limitación para mezclar los usos del suelo obliga a la población a recorrer amplias distancias para llegar a las plazas comerciales o a los sitios de entretenimiento,

\section{Cuadro 7.}

Topografía del fraccionamiento cerrado

\begin{tabular}{|c|c|c|c|c|c|c|c|c|}
\hline \multirow{2}{*}{ Ciudad } & \multicolumn{2}{|c|}{$\begin{array}{l}\text { Sobre } \\
\text { pendiente } \\
\text { ligera }\end{array}$} & \multicolumn{2}{|c|}{$\begin{array}{c}\text { Sobre } \\
\text { pendiente } \\
\text { pronunciada }\end{array}$} & \multicolumn{2}{|c|}{$\begin{array}{l}\text { Sobre } \\
\text { suelo } \\
\text { plano }\end{array}$} & \multicolumn{2}{|c|}{$\begin{array}{c}\text { Situación } \\
\text { de } \\
\text { riesgo }^{\mathrm{a}}\end{array}$} \\
\hline & Abs. & $\%$ & Abs. & $\%$ & Abs. & $\%$ & Abs. & $\%$ \\
\hline Tijuana & 26 & 36.1 & 33 & 45.8 & 13 & 18.0 & 35 & 48.6 \\
\hline Nogales & 3 & 27.2 & 8 & 72.7 & 0 & & 8 & 72.7 \\
\hline Ciudad Juárez & 2 & 5.5 & 0 & & 34 & 94.4 & 15 & $41-6$ \\
\hline Total & $3 \overline{3}$ & 27.7 & 39 & 32.7 & 47 & 39.4 & 58 & 48.7 \\
\hline
\end{tabular}

a Erosión, cauce de río, derrumbe, inundación. Fuente: Elaboración propia. 
lo que inhibe la movilidad peatonal y una imagen urbana diversificada. En fraccionamientos cerrados de grandes dimensiones y de interés social, con carencias de equipamientos comerciales y recreativos, se favorece la aparición del comercio informal con la oferta de servicios diversos en los domicilios y los tianguis de fin de semana, como se observa en El Dorado y Lomas Virreyes.

La voracidad de las inmobiliarias, los altos costos del suelo urbano y el régimen de condominio influyen en la calidad de los equipamientos de los fraccionamientos cerrados. Los fraccionamientos de nivel medio y alto se caracterizan por contar con áreas de equipamiento colectivo y áreas verdes de mayor calidad, cualidad que se incorpora a la promoción de los espacios cerrados resultando atractiva para la clase media por los mensajes alusivos a la tranquilidad y la armonización de la vida familiar; sin embargo, en la realidad esos equipamientos se circunscriben a los mínimos en metros cuadrados exigidos por las leyes estatales, resultando en muchos casos áreas bastante exiguas y difíciles de aprovechar por los residentes. De acuerdo a las fichas de campo, $43 \%$ de los fraccionamientos cuenta con un parque central de pequeñas dimensiones, en $6.9 \%$ hay una casa-club, en $11.1 \%$ se tienen áreas deportivas equipadas con juegos infantiles y habilitadas como locales de fiestas, y en $56.9 \%$ existen pequeñas áreas verdes a modo de jardín en espacios intersticiales imposibles de lotificar o utilizar como suelo residencial (cuadro 8).

En ningún fraccionamiento se localizaron áreas peatonales o andadores que favorezcan la circulación de personas y la comunicación entre las diversas secciones de los conjuntos. Los equipamientos educativos públicos o privados se ubican de manera periférica sobre suelo menos idóneo y con dificultades para satisfacer la demanda. Asimismo, ningún fraccionamiento cerrado cuenta con plantas de tratamiento de aguas negras o una política sustentable de manejo de la basura.

Por otra parte, los materiales de construcción utilizados en la edificación de viviendas son inapropiados para las condiciones climáticas de la región, pues se prefiere la solidez estructural otorgada por los materiales industrializados sin considerar las variaciones de temperatura y humedad. De ese modo, $62.5 \%$ de los fraccionamientos utili- 
Cuadro 8.

Equipamiento de los fraccionamientos cerrados

\begin{tabular}{lrrrrrrrrrrr}
\hline \multicolumn{1}{c}{ Tipo } & Parque & \multicolumn{2}{c}{$\begin{array}{c}\text { Casa } \\
\text { club }\end{array}$} & \multicolumn{2}{c}{$\begin{array}{c}\text { Inst. } \\
\text { deportivas }\end{array}$} & \multicolumn{3}{c}{ Comercio } & \multicolumn{2}{c}{$\begin{array}{c}\text { Área } \\
\text { verde }\end{array}$} \\
Ciudad & & Abs. & $\%$ & Abs. $\%$ & Abs. & $\%$ & Abs. \% & Abs. & $\%$ \\
\hline Tijuana & 31 & 43.0 & 5 & 6.9 & 8 & 11.1 & 5 & 6.9 & 41 & 56.9 \\
Nogales & 6 & 54.5 & 1 & 9.0 & 2 & 18.1 & 1 & 9.0 & 8 & 72.7 \\
Ciudad Juárez & 23 & 63.8 & 1 & 2.7 & 4 & 11.1 & 1 & 2.7 & 29 & 80.5 \\
\hline
\end{tabular}

Fuente: Elaboración propia.

zan el block de cemento y $37.5 \%$ el concreto armado en moldes, materiales empleados en la hechura de las paredes y techos para construir viviendas de manera rápida y estandarizada.

Como consecuencia, los espacios cerrados mantienen equipamientos muy limitados que no fomentan la integración social. Tal es el caso de los grandes fraccionamientos de interés social, donde las áreas verdes y los equipamientos deportivos se concentran en un sector determinado y son de dimensiones insuficientes para ser aprovechados por los habitantes. De ese modo, las privadas carecen de áreas para la convivencia general restringiendo la socialización y generando conflictos entre vecinos. En contrapartida, los fraccionamientos medios y altos incorporan mejores áreas colectivas y mayores áreas verdes, cualidades que explican el éxito de la propuesta cerrada entre las clases más pudientes de la ciudad; sin embargo, la exclusividad de la que gozan hace inaccesible el espacio a los demás miembros de la ciudad y la posibilidad de crear condiciones de sustentabilidad urbana se restringen.

Nogales guarda condiciones muy semejantes a Tijuana, aunque en menor escala en cuanto a la posibilidad del fraccionamiento cerrado para contribuir a una adecuada sustentabilidad urbana. El caótico y desordenado crecimiento urbano ocurrido en los últimos 20 años presenta hoy un panorama desalentador en cuanto a la factibilidad futura de la ciudad; en ese sentido, por su carga basada en la exclusividad 
el fraccionamiento cerrado puede reproducir una forma urbana tendiente a la exclusión. De acuerdo a opiniones obtenidas en las entrevistas realizadas, los habitantes de los fraccionamientos consideran sus espacios como seguros y tranquilos dentro de la agitada vida urbana, pero esas percepciones parten de valorar sus particulares condiciones de vida respecto a los problemas de la ciudad, sin contemplar las posibles consecuencias que el diseño urbano y la arquitectura del espacio cerrado puedan tener.

Es cierto que el fraccionamiento cerrado en la ciudad de Nogales ha redensificado áreas baldías dejadas por el proceso de especulación del suelo urbano y por las condiciones topográficas que dificultan la construcción de viviendas. El 63.6\% de los fraccionamientos cerrados se ha establecido en pequeños intersticios dejados en colonias populares, como los casos de La Riviera, El Paseo, Los Girasoles y Tres Tesoros. Estos espacios tienen como particularidad el estar rodeados por colonias populares abiertas, por lo cual la exclusividad de los pequeños conjuntos cerrados es contrastante y notoria. El 27.2\% de los fraccionamientos cerrados se ubica en la periferia de la ciudad, como Santa Lucía, San Alberto y Casablanca, emplazamientos cercanos a parques industriales de maquiladoras y con condiciones de terreno difíciles, por lo cual son espacios inaccesibles y sin ligas a la mancha urbana. Además, por encontrarse en la periferia de Nogales estos fraccionamientos mantienen dimensiones mayores en cuanto al número de viviendas construidas respecto a los ubicados al interior de la ciudad. Así, por ejemplo, Santa Lucía sería el fraccionamiento cerrado más grande de la ciudad, a pesar de sus escasas 200 viviendas.

Al igual que en Tijuana, la población de la ciudad prefiere vivir en viviendas unifamiliares. El 100\% de los conjuntos detectados tiene un diseño arquitectónico de tipo horizontal. Pretendiendo optimizar el escaso suelo urbano, $72.7 \%$ de los fraccionamientos está conformado por viviendas unifamiliares de dos plantas. Los materiales de construcción más utilizados en la construcción de viviendas son el block de cemento y el ladrillo. El 54.5\% de los fraccionamiento está construido con block de cemento, material barato pero poco adecuado por no tener las propiedades aislantes y térmicas necesarias dadas las condiciones extremas de temperatura de la ciudad. 
La superficie de la ciudad, formada por cerros y lomas de baja altura, dificulta el establecimiento de asentamientos humanos y la introducción de servicios e infraestructura, por ese motivo las inmobiliarias tienen que modificar el terreno para construir viviendas. El 72.7\% de los fraccionamientos se localiza sobre pendientes muy pronunciadas, en las faldas de los cerros o en el fondo de las cañadas. La topografía montañosa de Nogales influye también para crear condiciones de riesgo en los asentamientos construidos por los movimientos de tierra realizados para emparejar el suelo y construir muros de contención, así como por el taponamiento de cauces de arroyo y los taludes formados para crear niveles. En ese sentido, $72.7 \%$ de los fraccionamientos detectados presenta vulnerabilidad a inundaciones, erosión y derrumbes. En general, ningún espacio cerrado mantiene la flora del lugar; encinos, cactus y mezquites son arrasados de la superficie sin consideraciones ambientales, para ser reemplazados por plantas de ornato y árboles no apropiados para resistir el clima extremo del invierno.

La naturaleza exclusiva del fraccionamiento cerrado obliga a restringir un uso mixto del suelo. Sólo en un fraccionamiento se dispone de área comercial en un domicilio familiar, pero fue a demanda de los mismos residentes. Salvo el fraccionamiento Kennedy, orientado a la clase media alta de la ciudad, el resto presenta serias insuficiencias en cuanto a equipamientos recreativos y áreas verdes. En cuatro fraccionamientos cerrados, la organización vecinal tuvo que encargarse de defender las pocas áreas verdes y espacios de uso común disponibles de la voracidad de las inmobiliarias que deseaban venderlas como lotes urbanizados.

Ciudad Juárez tiene muy bien consolidado el fenómeno de los fraccionamientos cerrados, orientado primordialmente a la creación de desarrollos de nivel medio y alto. Esto propicia que los espacios sean cada vez más exclusivos e inaccesibles a intromisiones extrañas, y privilegia el confinamiento de los fraccionamientos en áreas aisladas del entorno urbano. El discurso de lo cerrado, presente tanto en las inmobiliarias como en los residentes, pugna por espacios tranquilos, seguros y bien construidos y que fomenten el sentido de comunidad, pero al mismo tiempo defiende una hechura urbana que 
prescinde de la ciudad, la excluye y reniega de ella estableciendo barreras físicas.

El fraccionamiento cerrado tiene un efecto muy limitado en la sustentabilidad urbana que alcanza sólo a los miembros elegidos para vivir en esos espacios. La segregación socioespacial es muy evidente en Ciudad Juárez. Los grupos sociales más acomodados económicamente tienden a establecerse en un cuadrado que va del centro hacia el oriente y nororiente de la ciudad sobre antiguos campos agrícolas, formando una periferia exclusiva donde el confort y el estatus son sobresalientes. Este sector nororiental concentra el grueso de los fraccionamientos cerrados de nivel medio y alto, es decir, se orienta a un sector con alta capacidad económica. Toda el área es vendida por las inmobiliarias bajo el supuesto de que los residentes hallarán tranquilidad, seguridad, confianza, plusvalía y comunidad en sana convivencia. Para cumplir con esos ideales, las viviendas deben tener ciertas características, de manera que el 100\% de los conjuntos mantiene casas unifamiliares, con lotes de mayores dimensiones y áreas comunes abundantes, a lo que contribuyen la topografía plana de la ciudad y la abundancia de suelo urbano en el sector. Aún así, en los 36 casos detectados las viviendas son de dos niveles para optimizar el suelo y ofrecer más metros cuadrados de construcción por vivienda.

En cuanto a los materiales de construcción utilizados para la edificación de viviendas, predomina el ladrillo y el block de cemento, pero también se innova con la utilización de materiales industrializados con propiedades térmicas para proteger del frío o del calor como el panel w, el foam block, el poliestireno espreado y texturizados elastoméricos en las paredes exteriores, como se observa en los fraccionamientos Tres Torres y Las Aldabas.

En cuanto a equipamientos comunes, el diseño urbano se basa en el circuito cerrado alrededor de un área central, que por lo general es ocupada por parques con abundante vegetación no nativa de la región y césped, juegos infantiles y cancha de básquetbol. El 63.8\% de los fraccionamientos cuenta con un parque central, en $11.1 \%$ existe equipamiento deportivo con casa-club y en $80.5 \%$ existen áreas verdes dispuestas en el acceso principal, en camellones y en glorietas de las calles interiores. En $63.6 \%$ de los fraccionamientos se detectaron 
andadores peatonales decorados con abundante vegetación, equipamiento que sirve no para comunicar las diversas áreas, sino más bien como espacio deportivo.

A diferencia de Tijuana y Nogales, la topografía plana de Ciudad Juárez contribuye a crear condiciones más benévolas para el desarrollo urbano. El 94.4\% de los fraccionamientos cerrados se encuentra sobre suelo plano y sólo $5.5 \%$ en terrenos con pendientes muy ligeras. El particular suelo plano influye también para vulnerar los asentamientos cerrados. En el trabajo de campo se observó que $41.6 \%$ de los fraccionamientos presentaba riesgo de inundación por escurrimientos pluviales. En el resto de los fraccionamientos se detectaron pozos de absorción en las áreas de uso común para contrarrestar la amenaza del agua, o también se aprovechan las antiguas acequias que recorren el sector para encauzar el agua hacia los canales.

$\mathrm{Al}$ estar aislados del entorno urbano, sobre suelo agrícola, los fraccionamientos cerrados en Ciudad Juárez no mantienen adyacencia con barrios o colonias pobres, por lo cual las distancias sociales no son tan perceptibles como en Tijuana y Nogales. Sin embargo, el confinamiento del fraccionamiento cerrado al oriente se contrarresta con la accesibilidad que presentan estos espacios con los centros comerciales, educativos y recreativos de la ciudad. Las obras de modernización urbana emprendidas en el sector permiten una conexión rápida y funcional con los sectores de la ciudad. La eficiente red vial y la ubicación de los conjuntos cerca de vialidades primarias fomentan el uso del vehículo privado. El $69.4 \%$ de los fraccionamientos está conectado a vialidades importantes.

El fenómeno de los fraccionamientos cerrados en Ciudad Juárez da buena cuenta del proceso de segregación socioespacial. La accesibilidad del espacio cerrado para conectarse a la infraestructura urbana no es compensada con la accesibilidad al interior de esos espacios. Las contribuciones a la sustentabilidad urbana son cuestionables en la medida en que los efectos positivos del fraccionamiento cerrado sólo tienen un alcance limitado a sus usuarios. El fraccionamiento cerrado refiere la construcción de ciudad extensa privilegiando la periferia como sinónimo de aislamiento y estatus, abandonando el área central de la ciudad y excluyéndola mediante una burbuja de protec- 
ción. De igual modo, el discurso "verde" presente en los fraccionamientos cerrados gracias a su emplazamiento en suelo agrícola y con microclima más benigno reproduce más un patrón de obtención de prestigio que de recuperación ecológica del ecosistema desértico. Lo "verde" es solamente un recurso ornamental.

En las tres ciudades fronterizas el fenómeno de los fraccionamientos cerrados no tiene consecuencias positivas en la sustentabilidad urbana. Si bien se detecta la presencia de procesos de redensificación, sus alcances son limitados y se circunscriben a la creación de zonas de exclusión. La expansión del fraccionamiento cerrado a las periferias de las ciudades no es resultado de una política tendiente a la recuperación de las áreas centrales o al abatimiento de los problemas urbanos, sino se trata más que nada de un proceso especulativo realizado por las inmobiliarias que pretenden maximizar las ganancias ofreciendo un modelo presuntamente alternativo a la inseguridad bajo la cual se vive en las ciudades.

La característica del fraccionamiento cerrado que menos contribuye a la sustentabilidad urbana de las ciudades fronterizas es la segregación socioespacial, pues la promesa de tranquilidad, seguridad y confort se circunscribe a unos pocos habitantes. El establecimiento de muros, casetas de vigilancia y guardias privados favorece la separación entre los grupos sociales, y no sólo no fomenta la diversidad, sino que privilegia la exclusividad cuando se trata de espacios para grupos de altos ingresos; además, reproduce una forma urbana basada en la discontinuidad y la fragmentación espacial por las barreras establecidas.

\section{Segregación urbana}

Los fraccionamientos cerrados existentes en las ciudades fronterizas expresan segregación social, es decir, el escenario urbano se ve sujeto a la separación espacial de los grupos sociales de acuerdo a su capital económico. Para el caso de las ciudades fronterizas, se entiende que la segregación social se basa en las diferencias en el nivel de ingresos de la población. De ese modo, las clases sociales más privilegiadas tienen la oportunidad de elegir dónde vivir, mientras las menos favore- 
cidas se ven condicionadas a la informalidad en la tenencia de la tierra o se atienen a las políticas públicas en materia de vivienda.

La condición socioeconómica es indispensable para explicar la proliferación de fraccionamientos cerrados en las ciudades fronterizas (cuadro 9). Estos espacios indican que las barreras físicas - muros, casetas de vigilancia y guardias privados - devienen barreras sociales. En el trabajo de campo se detectaron y ficharon 119 fraccionamientos cerrados en las ciudades fronterizas, sobresaliendo los residenciales medios y altos como los más numerosos. El cuadro 9 muestra cómo la segregación social se espacializa de acuerdo a la condición socioeconómica.

En las ciudades fronteriza el fenómeno de los fraccionamientos cerrados se orienta a las clases media y alta, siendo $50.4 \%$ conjuntos de nivel medio, $32.7 \%$ de nivel alto y sólo $16.8 \%$ de interés social. Como ya se ha comentado, los fraccionamientos cerrados de interés social se caracterizan por sus grandes dimensiones y por mantener alta densidad poblacional, en tanto los residenciales medios y altos son más pequeños en dimensiones y con menos densidad poblacional, pero más exclusivos por las restricciones existentes, la calidad de las viviendas y los equipamientos y el endurecimiento de las medidas de protección. La novedad que introduce el fraccionamiento cerrado en cuanto a la segregación social es la visibilidad de los obstáculos materiales en el tejido urbano, la imperceptibilidad del espacio interior de los conjuntos y la expansión del fenómeno en el escenario urbano.

Cuadro 9.

Nivel socioeconómico del fraccionamiento cerrado

\begin{tabular}{lrcrrrrr}
\hline \multirow{2}{*}{ Nivel } & \multicolumn{2}{c}{ Alto } & \multicolumn{3}{c}{ Medio } & \multicolumn{3}{c}{ Interés social } & \multirow{2}{*}{ Total } \\
& Abs. & \multicolumn{1}{c}{$\%$} & \multicolumn{1}{c}{ Abs. } & $\%$ & Abs. & $\%$ & \\
\hline Ciudad & 25 & 34.7 & 33 & 45.8 & 14 & 19.4 & 72 \\
Nogana & 2 & 18.2 & 7 & 63.6 & 2 & 18.2 & 11 \\
Ciudad Juárez & 12 & 33.3 & 20 & 55.5 & 4 & 11.1 & 36 \\
Total & 39 & 32.7 & 60 & 50.4 & 20 & 16.8 & 119 \\
\hline
\end{tabular}

Fuente: Elaboración propia. 
Pero al mismo tiempo que son más visibles los efectos defensivos de los muros y las casetas en el entramado urbano, también son más explícitas las diferencias sociales.

La segregación de los espacios se observa en la tendencia a ubicarse de forma aislada sin vínculos con los lugares contiguos, conectados a vialidades primarias y cercanos a áreas comerciales importantes de las ciudades; además, el diseño urbano apunta a satisfacer las necesidades de esparcimiento y ocio en el propio conjunto. En esta última necesidad tiene un papel significativo el proceso de privatización del espacio público. La capacidad económica es requisito básico para la oferta inmobiliaria de conjuntos urbanos provistos de dispositivos de seguridad y equipamientos superiores al promedio, que son demandados por los grupos sociales medios y altos por las posibilidades que ofrecen para mantener el estilo de vida y el prestigio social.

Es claro que existen diferencias en la oferta de conjuntos cerrados en las ciudades fronterizas de acuerdo a la condición de clase, resultando más desfavorecidos los residenciales de interés social en cuanto al diseño urbano, la calidad de las viviendas y la magnitud de los emprendimientos que pervierten las condiciones de habitabilidad, de lo que se desprende que el conjunto cerrado de interés social es más una caricatura que una propuesta de vida. El modelo cerrado está pensado para favorecer las condiciones de vida de las clases media y alta, de allí que sus atributos materiales y simbólicos endurecen la exclusividad y la seguridad; por el contrario, en los conjuntos de interés social se trata de un proceso inmobiliario que asegura la obtención de ganancias a partir de facilidades legales como el condominio, que permite crear asentamientos masivos y viviendas de reducidas dimensiones. En ese caso no existe posibilidad alguna para que los residentes obtengan prestigio social, pues la figura de la exclusividad es un mero argumento discursivo para vender y la seguridad una simulación. Las bases de la segregación social consisten en la reproducción de un efecto de normalización de la propuesta cerrada entre la población, pero dicha propuesta sólo se hace efectiva entre los grupos sociales con mayor capacidad económica.

En Tijuana, los fraccionamientos cerrados medios y altos en las zonas más exclusivas de la ciudad se distribuyen en los entornos de 
Agua Caliente, Playas de Tijuana y la línea costera hacia Rosarito. En cambio, los grandes asentamientos de interés social se establecen de manera periférica en suelo más barato, donde los problemas urbanos son más abrumantes en cuanto a seguridad, provisión de servicios básicos, condiciones de habitabilidad, cercanía con las áreas comerciales y laborales y disponibilidad de vialidades primarias. En ese sentido, la segregación social es notable entre los fraccionamientos medios y altos respecto a la ciudad y demás grupos sociales.

\section{Conclusiones}

Los planteamientos desarrollados a lo largo de este trabajo permiten reconocer que los fraccionamientos cerrados en las ciudades fronterizas de Tijuana, Nogales y Ciudad Juárez son consecuencia de procesos de fragmentación urbana que refuerzan un escenario caótico y desarticulado. La fragmentación actual de las ciudades fronterizas fomenta procesos que tienden a la dispersión, a incentivar las distancias sociales así como a acentuar la segregación de los habitantes. El importante crecimiento urbano sostenido en los últimos años ha significado una urbanización del territorio sin precisar sus límites. Las ciudades se desbordan continuamente por la magnitud del crecimiento sin obedecer a una estrategia definida que conjugue calidad de vida, fomento de la heterogeneidad social, adecuado nivel de participación ciudadana y presencia de un gobierno local fuerte. Más bien prevalece la imagen del caos y el desorden en la hechura urbana, con deficiencias en la dotación de infraestructura y equipamiento, alto nivel de polarización social, inseguridad evidente y gobiernos débiles e incapaces de regular el mercado inmobiliario o imponer el limitado marco normativo.

El fraccionamiento cerrado también tiene consecuencias negativas para las ciudades fronterizas. Restringe los usos mixtos del suelo, desmerece la accesibilidad urbana, favorece el aislamiento de zonas y establece barreras que acrecientan la incomunicación urbana. Entre los efectos negativos más evidentes se encuentra la segregación social, que convierte las barreras físicas de la seguridad en elementos que sostienen la exclusividad social. Los fraccionamientos medios y altos de Tijuana y Ciudad Juárez corroboran esa situación. También 
la privatización del espacio público es otro proceso aparejado al fortalecimiento del fraccionamiento cerrado. El diseño restrictivo del espacio fomenta la inaccesibilidad a los habitantes de las ciudades. Ligada al proceso de privatización del espacio público en las ciudades fronterizas, prospera la privatización de los servicios. La seguridad policiaca recae en cuerpos privados; los servicios de mantenimiento de los equipamientos recreativos y la conservación de las vialidades, así como la recolección de la basura, son tareas llevadas a cabo principalmente por servicios privados.

El fraccionamiento cerrado expresa el dominio del ámbito privado no sólo por la privatización del espacio público sostenido por la exclusividad y las restricciones de acceso, sino también por la segregación que se impone de acuerdo a la condición socioeconómica de la población. Los fraccionamientos cerrados expresan así una segregación basada en la condición social y económica de sus habitantes, no en términos étnicos, racionales o religiosos. El fraccionamiento cerrado de las ciudades fronterizas asume diferencias cualitativas y cuantitativas importantes de acuerdo a la clase social a la cual están destinados los conjuntos urbanos. Mientras que los fraccionamientos destinados a las élites cuentan con mejor equipamiento e infraestructura, mayor seguridad, menos población, más vías de acceso a la ciudad y mejores condiciones de habitabilidad, los fraccionamientos cerrados orientados a las clases sociales menos favorecidas son apenas una caricatura que simula las condiciones de su contraparte a costa de fragmentar la interacción social y reducir las condiciones de vida.

Es difícil pensar en qué medida el fraccionamiento cerrado contribuirá a crear ciudades más seguras, tranquilas, amables, cohesionadas y ordenadas, cuando en la práctica observamos que tiende a beneficiar solamente a determinados sectores sociales excluyendo al resto. Revertir el proceso de segregación social en las ciudades requiere forzosamente la conciliación de un fenómeno que en apariencia favorece la seguridad y la privacidad, confiere prestigio, densifica y compacta a las ciudades y presenta mejores equipamientos de uso colectivo y viviendas de calidad, pero al mismo tiempo restringe la diversidad de usos del suelo, la sustentabilidad y la conexión urbanas, la diversidad, la accesibilidad y la equidad social. 


\section{Bibliografía}

Carrasco Gallegos, Brisa, 2005, Comunidades cercadas y sustentabilidad urbana. Evaluación ambiental en Tijuana, México, tesis de maestría en Ciencias Sociales, El Colegio de Sonora.

López Levi, Liliana, 2005, “Nogales, ciudad y frontera: el sentido del encierro", en revista Imaginales, núm. 2, Universidad de Sonora, Hermosillo.

Lynch, Kevin, 1984, La imagen de la ciudad, Gustavo Gili, Barcelona.

Maycotte, Elvira, 2005, “Nuevas tipologías de vivienda de interés social financiadas por programas gubernamentales," ponencia presentada en el XXVIII Encuentro de la RNIU, Ciudad Juárez, septiembre de 2005.

Méndez, Eloy e Isabel Rodríguez, 2005, “Comunidades cercadas en la frontera México-Estados Unidos", en revista en línea Scripta Nova, vol. VIII, núm. 1711, Universidad de Barcelona, agosto de 2004, http:/ / www.ub.es/geocrit/sn-171.htm

, El "urbanismo defensivo", en revista Ciudades, núm. 59, julioseptiembre, RNIU, Puebla, México.

Muxi, Zaida, 2004, La arquitectura de la ciudad global, Gustavo Gili, Barcelona.

Quadri de La Torre, Gabriel, 2005, “Fox: vivienda sin ciudad”, El Economista, 21 de junio.

Rodríguez, Isabel, Eloy Méndez y Liliana López, 2006, Espacio urbano, exclusión y frontera norte de México, UNAM Ediciones, Madrid.

Sabatini, F. G. Cáceres y J. Cerda, 2001, “Segregación residencial en las principales ciudades chilenas: tendencias de las últimas tres décadas y posibles cursos de acción", en revista electrónica EURE, vol. 27, núm. 82 Santiago. www.scielu.cl/revistas/eure/ eaboutj.htm 